\title{
BMJ Open Prevalence and outcomes of twin pregnancies in Botswana: a national birth outcomes surveillance study
}

\author{
Arielle Isaacson (D) , ${ }^{1,2}$ Modiegi Diseko, ${ }^{2}$ Gloria Mayondi, ${ }^{2}$ Judith Mabuta, ${ }^{2}$ \\ Sonya Davey (1) , ${ }^{2,3}$ Mompati Mmalane, ${ }^{2}$ Joseph Makhema, ${ }^{2}$ Denise L Jacobson, ${ }^{4}$ \\ Rebecca Luckett, ${ }^{2,5}$ Roger L Shapiro, ${ }^{2,6}$ Rebecca Zash ${ }^{2,5}$
}

To cite: Isaacson A, Diseko M, Mayondi G, et al. Prevalence and outcomes of twin pregnancies in Botswana: a national birth outcomes surveillance study. BMJ Open 2021;11:e047553. doi:10.1136/ bmjopen-2020-047553

- Prepublication history for this paper is available online. To view these files, please visit the journal online (http://dx.doi org/10.1136/bmjopen-2020047553).

Received 08 December 2020 Accepted 24 September 2021

Check for updates

(C) Author(s) (or their employer(s)) 2021. Re-use permitted under CC BY-NC. No commercial re-use. See rights and permissions. Published by BMJ.

${ }^{1}$ Harvard Medical School, Boston, Massachusetts, USA

${ }^{2}$ Botswana-Harvard AIDS Institute Partnership, Gaborone, Botswana

${ }^{3}$ Brigham and Women's Hospital, Boston, Massachusetts, USA

${ }^{4}$ Center for Biostatistics and AIDS Research, Harvard University T H Chan School of Public Health, Boston,

Massachusetts, USA

${ }^{5}$ Beth Israel Deaconess Medical Center, Boston, Massachusetts, USA

${ }^{6}$ Harvard University T H Chan School of Public Health, Boston, Massachusetts, USA

Correspondence to Arielle Isaacson; arielleisaacson@hms.harvard. edu

\section{ABSTRACT}

Objectives This study aims to evaluate the prevalence and outcome of twin pregnancies in Botswana.

Setting The Tsepamo Study conducted birth outcomes surveillance at 8 government-run hospitals ( $45 \%$ of all births in Botswana) from August 2014 to June 2018 and expanded to 18 hospitals ( $70 \%$ of all births in Botswana) from July 2018 to March 2019

Participants Data were collected for all live-born and stillborn in-hospital deliveries with a gestational age (GA) greater than 24 weeks. This analysis included 117593 singleton and 3718 twin infants (1859 sets (1.6\%)) born to 119477 women between August 2014 and March 2019 and excluded 73 higher order multiples ( 23 sets of triplets and 1 set of quadruplets).

Outcomes measured Our primary outcomes were preterm delivery $(<37$ weeks $G A)$, very preterm delivery ( $<32$ weeks GA) and stillbirth (APGAR (Appearance, Pulse, Grimace, Activity, Respiration) score of $0,0,0$ ).

Results Women with twin pregnancies had a similar median number of antenatal care visits ( 9 vs 10), but were more likely to deliver in a tertiary centre $(54.8 \%$ vs $45.1 \%$, $\mathrm{p}<0.001$ ) and more likely to have a cesarean-section $(54.6 \%$ vs $22.0 \%, p<0.001)$ than women with singletons. Compared with singletons, twin pregnancies had a higher risk of preterm delivery (<37 weeks GA) $(47.6 \%$ vs $16.7 \%$, adjusted risk ratio (aRR) $2.8,95 \% \mathrm{Cl} 2.7$ to 2.9 ) and very preterm delivery ( $<32$ weeks) $(11.8 \%$ vs $4.0 \%$, aRR 3.0 $95 \% \mathrm{Cl} 2.6$ to 3.4). Among all twin pregnancies, 128 $(6.9 \%)$ had at least one stillborn infant compared with $2845(2.4 \%)$ stillbirths among singletons (aRR 2.8, 95\% Cl 2.3 to 3.3$)$.

Conclusion Adverse birth outcomes are common among twins in Botswana, and are often severe. Interventions that allow for earlier identification of twin gestation and improved antenatal management of twin pregnancies may improve infant and child survival.

\section{BACKGROUND}

Twin pregnancies are universally considered to be 'high risk'. Maternal complications, including hypertensive disorders, anaemia, postpartum haemorrhage and maternal mortality, are more common among twin pregnancies than singleton pregnancies. ${ }^{1}$ Twins are also more likely than singletons to
Strengths and limitations of this study

- Our study uses a large, nationally representative sample with little missing data.

- Due to the limited availability of early prenatal ultrasound, gestational age may be less accurate and we are unable to determine the cause of preterm birth or whether preterm birth is spontaneous.

- We are unable to evaluate the impact of preterm and low birth weight on longer-term outcomes of twins, or estimate perinatal mortality.

be born preterm and to have restricted growth in utero, thereby increasing their risk for intrauterine demise and neonatal mortality. ${ }^{2}$ The majority of existing research on multigravid pregnancies and birth outcomes among twins is from high-resource settings. ${ }^{3}$ In these settings, the perinatal mortality rate of twins is 3-7 times higher than that of singletons ${ }^{45}$ and up to $60 \%$ of twins are born preterm (before 37 weeks). ${ }^{67}$

In most high-resource settings, twin pregnancies are managed by routine prenatal monitoring and neonatal intensive care services, including early identification of twin pregnancies, serial antenatal ultrasound, referral to specialised centres and prenatal counselling. ${ }^{8} \quad$ In lower-resource settings, data are limited, but twin pregnancies may be at particularly high risk for adverse birth outcomes because of the lack of routine intensive prenatal monitoring and neonatal intensive care services. ${ }^{19}$ Additionally, maternal outcomes with multigravid pregnancies may also be worse because of limitations in management of maternal conditions more common in twin pregnancies, such as postpartum haemorrhage and pre-eclampsia. ${ }^{3}$

In Southern Africa, where assisted reproductive technology is not commonly available, the incidence of naturally occurring twins is estimated to be high (12-18 per 
1000 births) compared with other low-income and middle-income countries (LMIC) in East Asia and Latin America where the incidence of twins is as low as 6-9 per 1000 births. ${ }^{10}$ This relatively large number of twins may contribute substantially to perinatal mortality in the region. ${ }^{11}$ Increased prevalence of preterm delivery and low birth weight (LBW) among twins leads to increased risk of under-5 mortality due to malnutrition, respiratory disorders, vulnerability to infection and developmental delays. ${ }^{12}{ }^{13}$ It is estimated that one in five twins born in sub-Saharan Africa dies before the age of $5 .^{11}$ Prior studies of twins in sub-Saharan Africa predate implementation of the United Nations Sustainable Development Goals in 2015 and do not evaluate specific birth outcomes. ${ }^{9-12}$ This study focuses on Botswana, a country with a rapidly growing economy, strong investment in healthcare, a national programme to prevent maternal mortality, ${ }^{14}{ }^{15}$ and a large, nationally representative birth outcomes surveillance study (Tsepamo). We aim to provide the first published data on the prevalence and outcome of twin pregnancies in Botswana.

\section{METHODS}

\section{The Tsepamo Study}

The Tsepamo Study is a birth outcomes surveillance study in Botswana, where $>95 \%$ of women deliver in healthcare settings (not at home). ${ }^{16}$ Details of methodology have been previously published. ${ }^{17}{ }^{18}$ In summary, deidentified information was abstracted from obstetric cards (antenatal care records used throughout the pregnancy) at the time of discharge from the postnatal ward from women who deliver live-born or stillborn infants at select government maternity hospitals in Botswana. From August 2014 to June 2018 , data were collected from 8 sites across the country ( $45 \%$ of births in Botswana) and from July 2018 to March 2019 data were collected from up to 18 sites ( $72 \%$ of births in Botswana).

At each site, data were collected for all in-hospital deliveries with a gestational age (GA) greater than 24 weeks. Information included maternal demographics, antenatal care visits, ultrasound reports with date of ultrasound, HIV status, method of delivery and infant delivery characteristics (including the number of infants delivered, GA at delivery, birth weight and vital status at birth and discharge).

\section{Outcomes}

The primary adverse outcomes assessed were stillbirth Appearance, Pulse, Grimace, Activity, Respiration (APGAR) scores $0,0,0)$, preterm birth $(<37$ weeks gestation), very preterm birth ( $<32$ weeks gestation), LBW $(<2500$ g) and very LBW (VLBW) $(<1500$ g). While APGAR scores and birth weights were recorded for each individual twin, neonatal death status was only collected on the first twin per the original protocol of our study. Therefore, neonatal deaths in twins could not be analysed and were not included as a primary outcome assessed.
We chose not to provide data on neonatal deaths in twin 1 without data on twin 2 because it would only provide an incomplete comparison to singletons, which could over or underestimate the total Neonatal deaths (NND) among twins. The GA was documented by midwives at the time of delivery using the estimated delivery date, which is calculated at the first antenatal care visit based on the last reported menstrual period and confirmed by ultrasound when available. If the last menstrual period was unknown or suspected to be incorrect, and if no ultrasound data were available, midwives occasionally used fundal height measurements to estimate GA.

\section{Statistical analysis}

The prevalence of each birth outcome was calculated for singletons and twins and higher order multiples were excluded from analyses. Prevalence of preterm birth and very preterm birth were calculated per pregnancy as both twins were born at the same GA. Prevalence of stillbirth, LBW and VLBW among twins were calculated by pregnancy (defined as either twin with the outcome), and by infant (defined as the outcome in the total number of individual infants). When comparing birth outcomes between singletons vs twins, we used pregnancy as the unit of analysis (eg, how many pregnancies ended in at least one stillbirth). Log binomial regression models were fit to determine the relative risk (RR), adjusted risk ratio (aRR) and 95\% CIs of adverse birth outcomes among twin compared with singleton pregnancies. Multivariable models were adjusted for maternal age, gravida, educational attainment and maternal HIV status, which were chosen a priori based on prior analysis of risk factors for adverse birth outcomes in Tsepamo. ${ }^{17-19}$ Statistical analyses were performed using SAS software (Version 9.2).

\section{Patient and public involvement}

Patients and the public were not involved in the design or conduct of this study.

\section{RESULTS}

\section{Study population}

Between August 2014 and March 2019, there were 121 385 infants born to 119477 women who delivered in the Tsepamo Study, including 117593 (98.4\%) singletons, 3718 twin infants (1859 sets of twins) (1.6\%), 69 triplet infants (23 sets of triplets) $(0.00 \%), 4$ quadruplets (1 set) $(0.00 \%)$ and 1 with missing data for delivery number. GA was known in $98.8 \%$ of singletons and $98.7 \%$ of twins.

\section{Maternal characteristics and obstetric care}

Maternal demographics and obstetric care parameters are shown in table 1 . Women with twin pregnancies were older, less likely to be primigravid and more likely to have had $>4$ prior pregnancies compared with women with singleton pregnancies. The median number of antenatal care visits was similar among women with singletons (10) and women with twins (9). Prenatal ultrasound was 
Table 1 Maternal characteristics and obstetric care

\begin{tabular}{|c|c|c|}
\hline & $\begin{array}{l}\text { Twin pregnancies } \\
(\mathrm{N}=1859)\end{array}$ & $\begin{array}{l}\text { Singleton pregnancies } \\
(\mathrm{N}=117593)\end{array}$ \\
\hline \multicolumn{3}{|l|}{ Maternal characteristics } \\
\hline Missing & 0 & 71 \\
\hline Primigravid & $405(21.8 \%)$ & $42385(36.1 \%)$ \\
\hline Low maternal education (completed a none or primary only) & $167(9.2 \%)$ & $8624(7.5 \%)$ \\
\hline Missing & 55 & 2934 \\
\hline Botswana citizen & $1761(94.7 \%)$ & $113386(96.4 \%)$ \\
\hline Non-citizen & $89(4.79 \%)$ & $3674(3.12 \%)$ \\
\hline \multicolumn{3}{|l|}{ Obstetric care } \\
\hline Antenatal care visits (median, IQR) & $9(6-12)$ & $10(7-12)$ \\
\hline Missing (\%) & $21(1.1 \%)$ & $1112(1.0 \%)$ \\
\hline \multicolumn{3}{|l|}{ Ultrasound } \\
\hline Total with ultrasound during pregnancy ${ }^{\star}$ & $980 / 1248(78.5 \%)$ & $52,012 / 77786(66.9 \%)$ \\
\hline Median gestational age at ultrasound & $25(19,31)$ & $27(20,33)$ \\
\hline Ultrasound scan <20 weeks gestation & 243/1199 (20.3\%) & 10706/73522 (14.6\%) \\
\hline Missing ultrasound date & 49 & 4264 \\
\hline
\end{tabular}

${ }^{*}$ Captured in Tsepamo beginning 31 March 2016

performed in $78.5 \%(980 / 1248)$ of women with twin pregnancies at a median GA of 25 (IQR 19-31) weeks ( $20.3 \%$ prior to 20 weeks GA). In comparison, $66.9 \%$ (52 012/77 786) of women with singleton pregnancies received an ultrasound scan, at a median GA of 27 (IQR 20-33) weeks ( $14.6 \%$ prior to 20 weeks GA). Twins were more likely to be delivered in a tertiary hospital $(54.8 \%$ vs $45.1 \%$ ) and also more likely to deliver via caesarean section (C-section) (54.6\% vs $22.0 \%$ ).

\section{Birth outcomes}

The median GA was 39 weeks (IQR 37-40), and the median birth weight was $3080 \mathrm{~g}$ (IQR 2750-3400) among all singletons with 114749 (97.6\%) infants live-born. Among twin pregnancies, the median GA was 37 weeks (IQR 34-38) and the median birth weight was $2330 \mathrm{~g}$ (IQR 1920-2675) for the first twin and $2290 \mathrm{~g}$ (IQR 18302610) for the second twin with 3552 (95.5\%) infants liveborn. The mean head circumference was $32.4 \mathrm{~cm}$ for both the first and second twin, and slightly lower than the mean head circumference for singletons $(34.2 \mathrm{~cm})$.
Mean length at birth was similar for the first and second twin ( $45.7 \mathrm{~cm}$ and $45.4 \mathrm{~cm}$, respectively) but lower than the mean length of singletons $(50.1 \mathrm{~cm})$.

Twin pregnancies were more likely to result in preterm birth than singleton pregnancies (table 2). Compared with singletons, twin pregnancies had a higher risk of preterm birth $(47.6 \%$ vs $16.7 \%$, aRR $2.8,95 \%$ CI 2.7 to $3.2 .9)$ and very preterm birth $(11.8 \%$ vs $4.0 \%$, aRR 3.0 , $95 \%$ CI 2.6 to 3.4 ). C-sections were more common in preterm twins than preterm singletons ( $47.7 \%$ vs $23.0 \%)$, however, among very preterm births (<32 weeks GA), C-section rate was similar (24.9\% vs $22.7 \%)$.

Among all 3718 individual twin infants, $2397(64.5 \%)$ were LBW, 508 (13.7\%) were VLBW and 166 (4.5\%) were stillborn. Both twins were LBW in $52 \%$ of pregnancies, VLBW in $10.6 \%$ of pregnancies and stillborn in $2.0 \%$. The first born twin and the second born twin had similar rates of low and VLBW, but twin 2 was more likely to be stillborn than twin $1(5.2 \%$ vs $3.8 \%)$ (table 3$)$. The risk of at least one infant being LBW (aRR 4.5, 95\% CI 4.3 to 
Table 2 Preterm birth among twin and singleton pregnancies

\begin{tabular}{lcccc} 
& $\begin{array}{l}\text { Twin pregnancies } \\
\text { (N=1859) }\end{array}$ & $\begin{array}{l}\text { Singleton pregnancies } \\
\text { (N=117 593) }\end{array}$ & Relative risk & \multicolumn{1}{c}{$\begin{array}{l}\text { Adjusted relative } \\
\text { risk }^{*}\end{array}$} \\
\hline Preterm birth (<37 weeks) & $873(47.6 \%)$ & $19462(16.7 \%)$ & $2.8,95 \% \mathrm{Cl} 2.7$ to 3.0 & $2.8,95 \% \mathrm{Cl} 2.7$ to 2.9 \\
\hline Missing (\%) & $25(1.3)$ & $1391(1.2)$ & & \\
Very preterm birth (<32 weeks) & $217(11.8 \%)$ & $4664(4.0 \%)$ & $2.9,95 \% \mathrm{Cl} 2.6$ to $3.4 \quad 3.0,95 \% \mathrm{Cl} 2.6$ to 3.4 \\
\hline Missing (\%) & $25(1.3)$ & $1391(1.2)$ & & \\
\hline
\end{tabular}

${ }^{*}$ Adjusted for maternal age, gravida and educational attainment and maternal HIV status.

4.6), VLBW (aRR 5.2, 95\% CI 4.7 to 5.8) or stillbirth (aRR $2.8,95 \%$ CI 2.3 to 3.3 ) was higher among twin pregnancies than singleton pregnancies (table 3 ).

\section{DISCUSSION}

We performed the first published analysis of the prevalence and outcomes of twin births in Botswana using nationally representative data from 2014 to 2019. Because of the absence of medically assisted reproduction, Botswana represents a particularly valuable opportunity to study naturally occurring rates and outcomes of twinning. We found that twin births occurred in 16 per 1000 pregnancies, a prevalence much higher than reported twinning rates in LMIC outside of sub-Saharan Africa. We also found that adverse birth outcomes were high among twin pregnancies, including a $6.9 \%$ stillbirth prevalence, almost 3-fold higher than stillbirths in singleton pregnancies $(2.4 \%)$.

The rate of twinning in our study, 16/1000 pregnancies, is consistent with previously reported high rates of naturally occurring twins in Southern Africa (12-15/1000 pregnancies in Namibia, South Africa and Lesotho and $15-18 / 1000$ pregnancies in Zimbabwe).$^{10}$ In contrast, very low twinning rates (6-9/1000 pregnancies) have been documented in LMIC across East Asia and Central and South America. ${ }^{10}$ Geographical differences in naturally occurring twin birth rates are primarily due to genetic, racial and ethnic differences in predisposition to dizygotic (DZ) twin birth. ${ }^{10}$ While the rate of twinning in Botswana is high compared with other LMIC, it is lower than that in many high-income countries (HICs), where the introduction of medically assisted reproduction has led to dramatic increases in twinning rates over the past several decades. In the USA, for example, the rate of twin births rose from 18.9 per 1000 births in 1980-33.9 per 1000 births in $2014 .^{2021}$

The prevalence of stillbirths among twin pregnancies in Botswana (6.9\%) is well above the WHO's target of under 12 stillbirths per 1000 births. ${ }^{22}{ }^{23}$ However, our prevalence is similar to that reported across sub-Saharan Africa, and lower than a reported $10.2 \%$ stillbirth prevalence among twins in one Nigerian study. ${ }^{24}$ In contrast, the prevalence of stillbirth in twins in Botswana is higher than in HICs such as the USA $(0.35 \%)^{25}$ and South Korea $(0.48 \%){ }^{26}$ The prevalence of stillbirth among singletons in our study is $2.4 \%$, which is nearly 10 times greater than that among singletons in many HICs. ${ }^{27}{ }^{28}$ While twin pregnancies are clearly particularly high-risk and contribute substantially to perinatal mortality, the high prevalence of stillbirths among all pregnancies in Botswana highlights a strong need for interventions to decrease stillbirths in the entire population.

The prevalence of preterm birth among twin pregnancies (46.\%) in Botswana is substantially higher than that among singleton pregnancies $(16.8 \%)$ and slightly higher than reported prevalence of preterm birth among twins in other sub-Saharan countries. ${ }^{24}$ However, prevalence of preterm birth with twin pregnancy in Botswana is lower than the USA, where $60 \%$ of twin pregnancies have preterm births. ${ }^{62}$ While the high prevalence of preterm births among twins in the USA may be partially attributed to the increased risk for preterm birth in multiple gestation, it may also be explained by clearer antenatal care guidelines and closer prenatal monitoring among twin pregnancies in the USA compared with Botswana. The high prevalence of preterm birth among twins in the USA is in line with the American College of Obstetrics and Gynecology's guidelines, which recommend timing delivery based on chorionicity (38 weeks for dichorionicdiamniotic, 34-36 6/7 weeks for monochorionic (MC)diamniotic, 32-34 for MC-monoamniotic) and delivery by 37-38 week's gestation in uncomplicated twin pregnancies to reduce the risk of stillbirth. ${ }^{29-32}$

The relatively low rate of preterm birth and high rate of stillbirth among twin pregnancies in Botswana raises the question of whether twin stillbirths in Botswana could be decreased by increasing delivery of high risk (MC-monoamniotic, MC-diamniotic) twin pregnancies between 34 and 37 weeks. ${ }^{31-33}$ To implement this type of change, improvements in proportion of ultrasound in the first trimester of twin pregnancy to identify chorionicity and to improve accuracy of GA dating would be needed. Additionally, preterm delivery may carry increased risk in lowresource settings like Botswana where intensive neonatal care services are limited. Though delivery by 37 weeks may not be appropriate in all settings, closer surveillance of twin pregnancies after 34 weeks GA, at which time the risk of stillbirth and maternal complications begins to rise, may improve twin outcomes in Botswana. ${ }^{26}$ Close monitoring for fetal growth concordance, ${ }^{34}$ screening for 


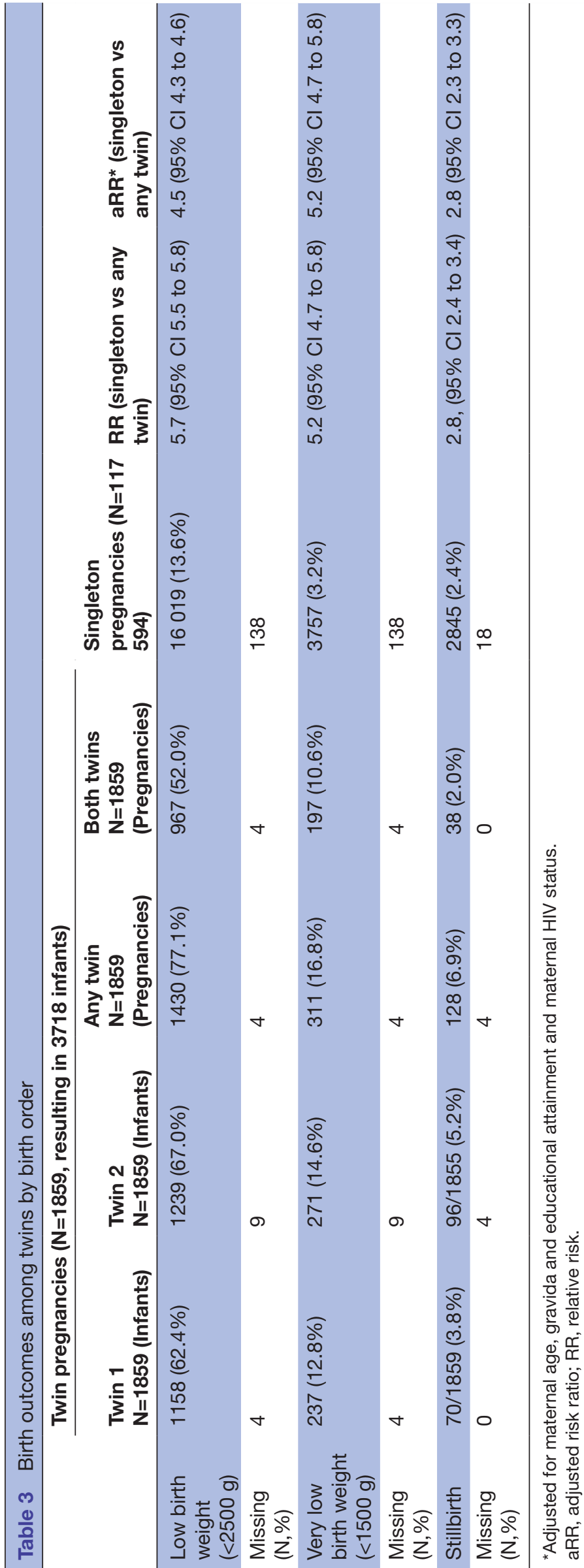


aneuploidy, which is more common among twin pregnancies and associated with higher risk of stillbirth, ${ }^{5} 36$ and clear delivery planning during antenatal care may also help to reduce adverse perinatal outcomes among twins. In addition to increased antenatal care, improvements in maternal nutrition may help improve outcomes in twin pregnancies in Botswana. Despite the relatively lower prevalence of preterm births in Botswana, we found very high rates of LBW and VLBW among twins $(77.2 \%$ and $16.8 \%$, respectively, compared with $55.6 \%$ and $9.1 \%$ in the USA), ${ }^{7}$ which is likely multifactorial, but suggests that women with twin pregnancies in Botswana may not receive adequate nutrition to support multiple gestations. ${ }^{37} 38$

Strengths of this study include the large, nationally representative sample with little missing data. Our study also has several limitations. Due to the limited availability of early prenatal ultrasound, GA may be less accurate. Also, our study did not collect information necessary to determine the aetiology of preterm delivery and stillbirth among twins, such as induction status, spontaneity of preterm delivery, whether c-sections were planned or emergent, indication for c-section (including presentation of infants), or fetal heartbeat on admission. Understanding the causes of adverse outcomes is clearly necessary before effective interventions can be designed and implemented. However, we hope our findings will be the catalyst for further research to elucidate these causes and ultimately lead to fewer adverse birth outcomes among twins. We are also unable to distinguish the proportion of twins that are MC, which is a known risk factor for stillbirth and neonatal death. ${ }^{9}{ }^{33}$ However, the prevalence of MC twins is thought to be relatively constant worldwide (prevalence of DZ twins varies), so this is unlikely to explain the high prevalence of stillbirth that we found among twin pregnancies in Botswana. ${ }^{39} 40$ Due to our study design, we are unable to evaluate the impact of preterm and LBW on longer-term outcomes of twins, or estimate perinatal mortality. Finally, we do not have data from deliveries occurring outside the hospital, though this is rare $(<5 \%)$ in Botswana. ${ }^{15} 16$

\section{CONCLUSIONS}

In summary, we found that the prevalence of twinning is high in Botswana and adverse birth outcomes are common among twin pregnancies and are often severe. The high rate of stillborn and LBW twins despite a relatively low preterm birthrate compared with twins in HICs points to the need for interventions that include early ultrasound and identification of twin gestation and type of twin gestation, improved maternal nutrition, close antepartum surveillance and advanced delivery planning in order to reduce morbidity and mortality among twin pregnancies in Botswana.

Acknowledgements We thank our research assistants Cynthia Dube, Daphne Segobye, Gosego Legase, Keemenao France, Mmapula Ofhentse, Naledi Kamanga,
Onkabetse Mokgosi, Rosemary Moremi, Shally Morgan, Tsaone Gaonakala, Tshepang Motlotlegi, Edith Moseki, Patricia Mophutegi, Keba Rabasiako, Nametsang Tshosa, Maipelo Kegakilwe, Masego Kgafela, Tshegofato Motladile, Tsholofelo Tsokunyane, Kealeboga Mmokele, Obakeng Makalane, Thuto Rabana, Seele Mafokate, Annah Bojang, Thhabologo Baitsemi, Priscilla Mashona and Bathoba Mabiletsa; the maternity staff and administrators at the 18 participating hospitals; the members of the Botswana Ministry of Health and Wellness and the Department of Maternal and Child Health.

Contributors $\mathrm{Al}$ and $\mathrm{RZ}$ designed and performed the analysis and drafted the initial manuscript. RL, JoM, MM, RZ and DLJ contributed to the design, data collection and study oversight of the parent study. GM, MD, JuM, SD and Al oversaw data collection and data cleaning. All authors (Al, MD, GM, JuM, SD, MM, JoM, DLJ, RL, RLS and RZ) contributed substantive feedback, revised and approved the final manuscript. $R Z$ is responsible for the overall content as the guarantor.

Funding Supported by grants from the Eunice Kennedy Shriver National Institute of Child Health and Human Development (NICHD), National Institutes of Health (R01 HD080471 and R01 HD095766, to RLS; and K23 HD088230, to RZ).

\section{Competing interests None declared.}

Patient and public involvement Patients and/or the public were not involved in the design, or conduct, or reporting, or dissemination plans of this research.

Patient consent for publication Not applicable.

Provenance and peer review Not commissioned; externally peer reviewed.

Data availability statement Data are available on reasonable request. Per Botswana IRB regulations, deidentified data from the Tsepamo study can be requested from the principal investigator of the study.

Open access This is an open access article distributed in accordance with the Creative Commons Attribution Non Commercial (CC BY-NC 4.0) license, which permits others to distribute, remix, adapt, build upon this work non-commercially, and license their derivative works on different terms, provided the original work is properly cited, appropriate credit is given, any changes made indicated, and the use is non-commercial. See: http://creativecommons.org/licenses/by-nc/4.0/.

\section{ORCID iDs}

Arielle Isaacson http://orcid.org/0000-0003-1743-4342

Sonya Davey http://orcid.org/0000-0003-4907-9920

\section{REFERENCES}

1 Hanson C, Munjanja S, Binagwaho A, et al. National policies and care provision in pregnancy and childbirth for twins in eastern and southern Africa: a mixed-methods multi-country study. PLoS Med 2019;16:e1002749.

2 Lawn J, Mongi P, Cousens S. Africa's newborns-counting them and making them count. In: Lawn J, Kerber K, eds. Opportunities for Africa's newborns: practical data, policy and programmatic support for newborn care in Africa. Cape Town: PMNCH, 2006: 11-22.

3 Bellizzi S, Sobel H, Betran AP, et al. Early neonatal mortality in twin pregnancy: findings from 60 low- and middle-income countries. $J$ Glob Health 2018;8:010404.

4 Peter C, Wenzlaff P, Kruempelmann J, et al. Perinatal morbidity and early neonatal mortality in twin pregnancies. Open J Obstet Gynecol 2013;03:78-89.

5 Hack KEA, Derks JB, Elias SG, et al. Increased perinatal mortality and morbidity in monochorionic versus dichorionic twin pregnancies: clinical implications of a large Dutch cohort study. BJOG 2008;115:58-67.

6 Murray SR, Stock SJ, Cowan S, et al. Spontaneous preterm birth prevention in multiple pregnancy. Obstet Gynaecol 2018;20:57-63.

7 Martin JA, Hamilton BE, Osterman MJ. Births: final data for 2018. National Vital Statistics 2019;68:47.

8 Christensen K, Bjerregaard-Andersen M. Twin-singleton early-life survival in sub-Saharan Africa. Lancet Glob Health 2017;5:e636-7.

9 Glinianaia SV, Obeysekera MA, Sturgiss S, et al. Stillbirth and neonatal mortality in monochorionic and dichorionic twins: a population-based study. Hum Reprod 2011;26:2549-57.

10 Smits J, Monden C. Twinning across the developing world. PLoS One 2011;6:e25239.

11 Monden CWS, Smits J. Mortality among twins and singletons in subSaharan Africa between 1995 and 2014: a pooled analysis of data from 90 demographic and health surveys in 30 countries. Lancet Glob Health 2017;5:e673-9. 
12 Justesen A, Kunst A. Postneonatal and child mortality among twins in southern and eastern Africa. Int J Epidemiol 2000;29:678-83.

13 Miyahara R, Jasseh M, Mackenzie GA, et al. The large contribution of twins to neonatal and post-neonatal mortality in the Gambia, a 5-year prospective study. BMC Pediatr 2016;16:39.

14 Mogobe KD, Tshiamo W, Bowelo M. Monitoring maternity mortality in Botswana. Reprod Health Matters 2007;15:163-71.

15 Madzimbamuto FD, Ray SC, Mogobe KD, et al. A root-cause analysis of maternal deaths in Botswana: towards developing a culture of patient safety and quality improvement. BMC Pregnancy Childbirth 2014;14:231.

16 Nkhwalume L, Mashalla Y. Maternal mortality trends at the Princess marina and Nyangabwe referral hospitals in Botswana. Afr Health Sci 2019;19:1833-40.

17 Zash R, Jacobson DL, Diseko M, et al. Comparative safety of antiretroviral treatment regimens in pregnancy. JAMA Pediatr 2017;171:e172222.

18 Zash R, Holmes L, Diseko M, et al. Neural-Tube defects and antiretroviral treatment regimens in Botswana. N Engl J Med 2019;381:827-40.

19 Zash R, Jacobson DL, Diseko M, et al. Comparative safety of dolutegravir-based or efavirenz-based antiretroviral treatment started during pregnancy in Botswana: an observational study. Lancet Glob Health 2018;6:e804-10.

20 Martin JA, Hamilton BE, Osterman MJ. Three decades of births in the United States, 1980-2009. Hyattsville, MD: National Center for Health Statistics, 2012: Report No.: 80

21 Martin JA, Osterman MJ. Is twin childbearing on the decline? twin births in the United States. Hyattsville, MD: National Center for Health Statistics, 2019: Report No.: 351.

22 Saleem S, Tikmani SS, McClure EM, et al. Trends and determinants of stillbirth in developing countries: results from the Global Network's Population-Based Birth Registry. Reprod Health 2018;15.

23 Lawn JE, Blencowe $\mathrm{H}$, Waiswa $\mathrm{P}$, et al. Stillbirths: rates, risk factors, and acceleration towards 2030. Lancet 2016;387:587-603.

24 Akaba GO, Agida TE, Onafowokan O, et al. Review of twin pregnancies in a tertiary hospital in Abuja, Nigeria. J Health Popul Nutr 2013;31:272-7.

25 Page JM, Pilliod RA, Snowden JM, et al. The risk of stillbirth and infant death by each additional week of expectant management in twin pregnancies. Am J Obstet Gynecol 2015;212:630.e1-630.e7.

26 Ko HS, Choi SK, Wie JH, et al. Optimal timing of delivery based on the risk of stillbirth and infant death associated with each additional week of expectant management in multiple pregnancies: a national cohort study of Koreans. J Korean Med Sci 2018;33:e80.

27 Flenady V, Wojcieszek AM, Middleton P, et al. Stillbirths: recall to action in high-income countries. Lancet 2016;387:691-702.

28 MacDorman MF, Gregory EC. Fetal and perinatal mortality: United States, 2013. National Vital Statistics Report 2015;64

29 Committee on Practice Bulletins - Obstetrics, Society for MaternalFetal Medicine. Practice Bulletin No. 169: multifetal gestations: twin, triplet, and higher-order multifetal pregnancies. Obstet Gynecol 2016;128:e131-46.

30 Dodd JM, Crowther CA, Haslam RR, et al. Timing of birth for women with a twin pregnancy at term: a randomised controlled trial. BMC Pregnancy Childbirth 2010;10:68.

31 Dodd JM, Crowther CA, Haslam RR, et al. Elective birth at 37 weeks of gestation versus standard care for women with an uncomplicated twin pregnancy at term: the twins timing of birth randomised trial. BJOG 2012;119:964-74

32 Wood S, Tang S, Ross S, et al. Stillbirth in twins, exploring the optimal gestational age for delivery: a retrospective cohort study. BJOG 2014;121:1284-90.

33 Cheong-See F, Schuit E, Arroyo-Manzano D, et al. Prospective risk of stillbirth and neonatal complications in twin pregnancies: systematic review and meta-analysis. BMJ 2016;354:i4353.

34 D'Antonio F, Odibo AO, Prefumo F, et al. Weight discordance and perinatal mortality in twin pregnancy: systematic review and metaanalysis. Ultrasound Obstet Gynecol 2018;52:11-23.

35 Shi X, Li L, Huang X, et al. Fetal aneuploidy: a comparison of Dichorionic twins and monochorionic twins. Fetal Diagn Ther 2018;44:124-8

36 Audibert F, Gagnon A. No. 262-Prenatal screening for and diagnosis of aneuploidy in twin pregnancies. J Obstet Gynaecol Can 2017;39:e347-61.

37 Luke B. Nutrition in multiple gestations. Clin Perinatol 2005;32:403-29.

38 Goodnight W, Newman R, Society of Maternal-Fetal Medicine. Optimal nutrition for improved twin pregnancy outcome. Obstet Gynecol 2009;114:1121-34.

39 Pison G, D'Addato AV. Frequency of twin births in developed countries. Twin Res Hum Genet 2006;9:250-9.

40 Hankins GVD, Saade GR. Factors influencing twins and zygosity. Paediatr Perinat Epidemiol 2005;19 Suppl 1:8-9. 